\title{
A case of Noonan's syndrome and hypoparathyroidism presenting with epilepsy
}

\author{
PETER RUDGE, B. G. R. NEVILlE, AND P. T. LASCELleS
}

From the National Hospitals for Nervous Diseases, Queen Square, London

SUMMARY A patient of 29 years is described with Noonan's syndrome and idiopathic hypoparathyroidism, who presented with epilepsy and myoclonus. Correction of the hypocalcaemia resulted in improvement of his myoclonus and psychiatric abnormalities. The embryological significance of the association is discussed.

In 1963 Noonan and Elimke described a condition resembling Turner's syndrome with female or male phenotype, right-sided congenital heart defects, and a normal karyotype (Noonan, 1968). Many cases have been reported since and the limits of Noonan's syndrome have become clearer, although its pathogenesis remains obscure (Smith, 1970). We report a further patient who presented with myoclonus and depression, and who proved to have hypoparathyroidism.

\section{CASE HISTORY}

The patient (National Hospital No. A11607) was the eldest of three children born to healthy unrelated parents and no member of the family shared his physical appearance. One sibling died of acute leukaemia and a maternal aunt died with a diagnosis of fibrous dysplasia and epilepsy.

The pregnancy was complicated by rubella at 14 weeks; the delivery at term was normal and apart from obvious webbing of the neck his neonatal condition was normal. His early development and progress at a normal school were slow, and he has had a number of unskilled jobs. He had been given routine immunizations including smallpox vaccination in infancy and BCG in his early teens because of a negative tuberculin test. There were no severe infective episodes in childhood, although he was slower to recover from infections than his siblings. He developed two typical attacks of measles at the age of 5 and 7, on both occasions after close contact with infection. In the late teens he was troubled by severe pustular acne over the face and neck.

In 1962 (aged 17 years) sporadic jumping of the limbs, head, and trunk began. These jerks occurred single or in runs, without aura or disturbance of consciousness, causing him to drop objects and occasionally fall to the ground. They were more frequent in the morning, aggravated by stress, disappeared in sleep, and were largely unaffected byc phenobarbitone and phenytoin. Remissions of several weeks were reported but from 1966 episodes $\rightarrow$ of status myoclonicus occasionally followed by grand mal attacks occurred.

He was admitted to the National Hospital is March 1969 (aged 24 years), when the abnorma appearance of the optic discs was noted. Nitrazepam $10 \mathrm{mg}$ daily produced good control of his myoclonus until June 1970, when he became depressed and took an overdose of anticonvulsant drugs. Although some improvement occurred in his psychiatric state, he remained subject to feelings of gloom and depression. The myoclonus again became troublesome in 1971, with two further major convulsions, and in March his anticonvulsant dosage was increased. After this he became aggressive, irritable, and complained of unsteadiness, slurring of speech, blurred vision, and increased jerking. He was readmitted to the National Hospital in April 1971 (aged 29 years).

Physical examination showed the typical facial and skeletal abnormalities of Noonan's syndrome: height $170 \mathrm{~cm}(10 \mathrm{~cm}$ less than expected from family measurements); bilateral ptosis with moderate epicanthic folds; a broad-tipped nose; simple low-set ears, with the inferior part placed abnormally far forward; ridged teeth with caries; marked webbing of the neck; a broad depressed sternum with laterally placed nipples; short distal phalanges to the thumbs; dystrophic nails; dry, hyperkeratotic skin; limitation of supination of the forearms: the fingers showed a low total ridge count of approximately 50 . In addi- 


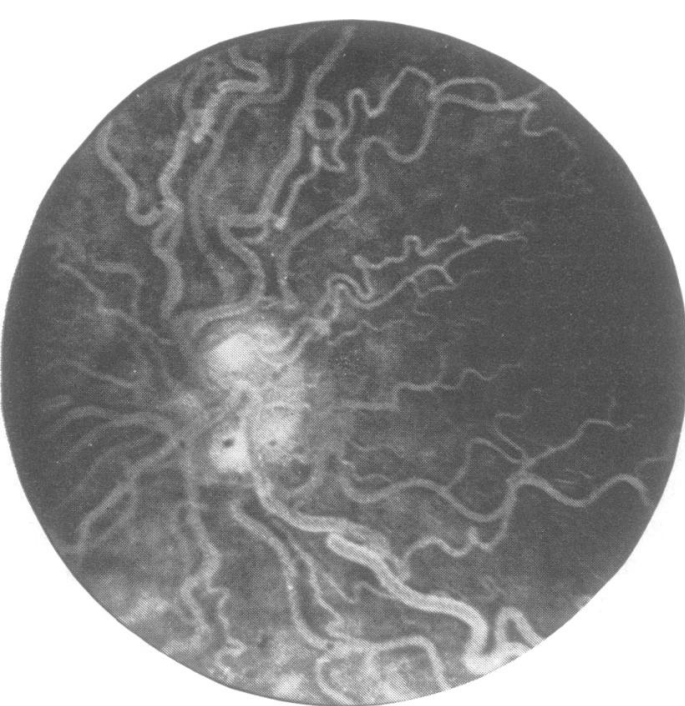

FIG. 1 Fluorescein angiogram, right eye, $5 \mathrm{~s}$ after injection.

tion, there was extensive pustular acne of the face and neck, particularly over the web folds. The genitalia were normal; there was no significant cardiac abnormality and he was normotensive.

At the time of admission, Trousseau's and Chvostek's signs were positive. The optic fundi were abnormal with very tortuous vessels and pink discs with clearly defined margins. In addition, he had the signs of phenytoin intoxication including drowsiness, nystagmus, impaired fixation of gaze, and ataxia. All these signs disappeared with reduction of the phenytoin dosage. There was no abnormality of tone or power in the limbs. The tendon reflexes were brisk and plantar responses flexor. Sensation was normal.

INVESTIGATIONS The following biochemical abnormalities were detected; with the normal range in parentheses: fasting serum calcium: 7.2 and $7.4 \mathrm{mg} /$ $100 \mathrm{ml}$. (9-10.5); fasting plasma inorganic phosphate: $5.1 \mathrm{mg} / 100 \mathrm{ml}$. as $\mathrm{P}(2.5-4.5)$; serum alkaline phosphatase: 106 i.u./l. and 69 i.u./1. (20-90); urinary calcium excretion: $59 \mathrm{mg}$ in 24 hours (100300); serum parathyroid hormone, measured by double antibody radio-immunoassay: $75 \mathrm{pg} / \mathrm{ml}$. $(385 \pm 37)$ (Fairney and Jackson, 1972); plasma phenytoin concentration: $33 \mu \mathrm{g} / \mathrm{ml}$. (therapeutic range 10-20).

Ellsworth Howard test Urinary inorganic phosphate excretion while on low phosphate diet: before parathormone: $31.2 \mathrm{mg} / \mathrm{hr} \mathrm{P}$; after parathormone (200 units intravenously): $76.0 \mathrm{mg} / \mathrm{hr}$ P. Phosphate excretion index: before parathormone: $-0 \cdot 15$; after parathormone: 0.0 ; normal range: $\pm 0.09 \%$.

Radiological studies showed an abnormally thick skull vault, with calcification of the falx but not in the brain parenchyma; a block vertebra in the

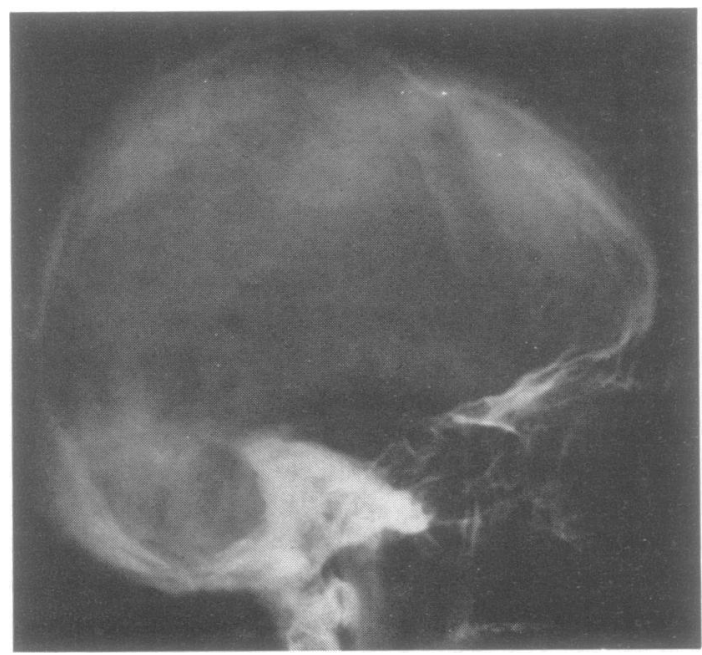

FIG. 2 Lateral radiograph of skull.

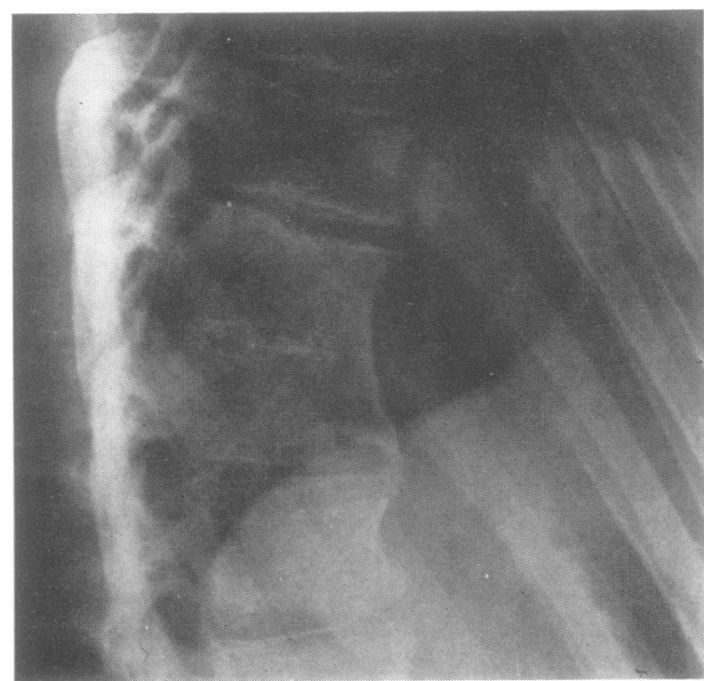

FIG. 3 Lateral radiograph of dorsal spine. 
scoliotic dorsal spine at D11-12, with calcification of the rudimentary disc; spina bifida at $\mathrm{C} 5,6$, and 7 vertebrae; normal limb bones apart from short distal phalanges of each thumb; and the remaining first and second molars had single roots.

The initial electroencephalographic records (EEG) in 1963 showed a slightly irregular $8 \mathrm{~Hz}$ rhythm, together with scattered low voltage slow waves. Superimposed on this were transients of several waves of $0 \cdot 3$ second duration, maximal bifrontally, and frequently preceded by spikes. Isolated spikes also occurred. Subsequent records showed essentially the same picture but with fluctuation of the transients. A record in April 1971 demonstrated a slower background rhythm of 6-7 Hz but with little evidence of paroxysmal activity.

In 1969, full scale IQ, using the WAIS, was 88 .

Fluorescein angiography confirmed the gross tortuosity and dilatation of the retinal vessels with many abnormal branches, but there was no leakage of dye.

Serum immunoglobulins and lymphocyte transformation to standard antigens were normal; measles antibodies were detected in the serum and the Mantoux reaction was positive at $1: 1,000$. The karyotype was of a normal male.

PROGRESS Calciferol $1.25 \mathrm{mg}$, calcium $400 \mathrm{mg}$ daily, and aluminium hydroxide were given and the serum calcium, phosphate, and alkaline phosphatase returned to normal over the next month with progressive improvement of mood and skin condition. Subsequently, he was maintained on calciferol and anticonvulsants. He has remained free of major convulsions and had only very occasional myoclonus. He was no longer depressed but occasionally became agitated.

Reduction of the phenytoin dose from $100 \mathrm{mg}$ to $50 \mathrm{mg}$ three times daily resulted in a fall of plasma phenytoin level to $18 \mu \mathrm{g} / \mathrm{ml}$. and a return of the basic EEG rhythm to $8 \mathrm{~Hz}$.

\section{DISCUSSION}

We know of no previous report of the association of hypoparathyroidism and Noonan's syndrome, although three patients with the skeletal features of brachymetacarpal dwarfism, female phenotype, and chromatin negative buccal smear tests have been reported (van der Werff ten Bosch, 1959). In addition, our patient had epilepsy and abnormal optic discs. There was no evidence of raised cerebrospinal fluid pressure at lumbar puncture and the disc did not leak fluorescein. The fundal abnormality, therefore, is likely to be congenital rather than secondary to hypocalcaemia.

The chemical findings are those of hypoparathyroidism; low serum and urinary calcium, very low serum parathyroid hormone level; a definite response to injected parathormone, and a chemical response to the standard dosage of vitamin $\mathrm{D}$. The patient had the typical stigmata of prolonged hypocalcaemia with dry skin, brittle nails, and carious teeth. The Ellsworth Howard test (Ellsworth and Howard, 1934) showed a normal two and a half fold increase of urine phosphate excretion in response to parathormone, although the absolute excretion was low on the low phosphate diet used during the test. Further, the phosphate excretion index (Hodgkinson, 1961) lay within the range found in hypoparathyroidism and reverted to normal after administration of parathormone. The initial, slightly raised, alkaline phosphatase waso probably due to long-term phenytoin intoxica tion.

Epilepsy is found in approximately $70 \%$ o patients with idiopathic hypoparathyroidism (Bronsky et al., 1958; Glasser and Levy, 1959-608 but myoclonus is unusual, although jerking of the limbs is described (Robinson et al., 1954)훌 Treatment of the hypocalcaemia is usually $\vec{y}^{+}$ accompanied by a reduction in the frequency of the fits (for example, Sugar, 1953). In hypocalcaemia, the EEG may show slow waves, spike and wave discharges, and single and multiple spikes as in this patient (Basser et al., 1969) and these may improve on treatment (Fourman et al., 1963). Psychiatric problems, particularly intellectual impairment and depression, are common in hypocalcaemia (Denko and Kaelbling, 1962) and the latter may recover after treatment.

The only clinical overlap between Noonan's syndrome and hypoparathyroidism is the mental dullness, dystrophic nails, and dry skin. Abnormalities of the neck and pinna are reported in children with hypoparathyroidism, particularly in the syndrome of congenital absence of parathyroid and thymus glands (DiGeorge, 1965). In the DiGeorge syndrome it is suggested that the major derivatives of 3rd and 4th pharyngeal pouches (Hamilton et al., 1962) and, presumably, the overlying branchial arches have failed to develop normally. The present patient 
did not have the main features of the DiGeorge syndrome: infection and hypocalcaemic convulsion in infancy and defective cellular imunity.

Hypoparathyroidism and abnormalities of face and ears have also been reported in a patient with ring chromosome no. 16 (Pergament et al., 1970). This infant presented with hypocalcaemic convulsions and had hypertelorism, epicanthic folds, a beaked nose, high palate, micrognathia, and low-set abnormal ears. These authors also referred to other reports of coexisting facial anomalies with hypoparathyroidism. It is possible, therefore, that the hypoparathyroidism in our patient is part of the developmental defect of the branchial arches which results in facial and neck abnormalities of Noonan's syndrome.

\section{ADDENDUM}

Since this paper was prepared, Tuvemo and Gustavson (1972) have reported on a 13 year old girl with clinically classical Turner's syndrome who presented with increasing irritability, fatigue, and failing school performance, and was found to have hypoparathyroidism. Cytogenetic studies showed mosaicism with a $45 \mathrm{XO}$ line and a 46 line with a structural chromosome defect. This report supports the view that hypoparathyroidism is associated with branchial arch defects rather than one particular syndrome.

We wish to thank Dr. A. Fairney for the parathyroid hormone estimation, Professor J. Southill for immunological investigations, and Dr. C. O. Carter and Professor R. W. Gilliatt for their helpful advice.

\section{REFERENCES}

Basser, L. S., Neale, F. C., Ireland, A. W., and Posen, S. (1969). Epilepsy and electroencephalographic abnormalities in chronic surgical hypoparathyroidism. Annals of Internal Medicine, 71, 507-515.

Bronsky, D., Kushner, D. S., Dubin, A., and Snapper, I. (1958). Idiopathic hypoparathyroidism and pseudohypoparathyroidism: case reports and review of the literature. Medicine (Baltimore), 37, 317-352.

Denko, J. D., and Kaelbling, R. (1962). The psychiatric aspects of hypoparathyroidism. Acta Psychiatrica Scandinavica, 38, Suppl. 164.

DiGeorge, A. M. (1965). A new concept of the cellular basis of immunity. Abstract. Journal of Pediatrics, 67, 907-908.

Ellsworth, R., and Howard, J. E. (1934). Studies on the physiology of the parathyroid glands. Bulletin of the Johns Hopkins Hospital, 55, 296-308.

Fairney, A., Jackson, D. B., and Clayton, B. E. Serum parathyroid hormone concentrations in hypocalcaemia of infancy. (In preparation.)

Fourman, P., Davis, R. H., Jones, K. H., Morgan, D. B., and Smith, J. W. G. (1963). Parathyroid insufficiency after thyroidectomy. British Journal of Surgery, 50, 608-619.

Glasser, G. H., and Levy, L. L. (1959/60). Seizures and idiopathic hypoparathyroidism. Epilepsia, N.S., 1, 454-465.

Hamilton, W. J., Boyd, J. D., and Mossman, H. W. (1962). Human Embryology, 3rd edn., p. 222. Heffer: Cambridge.

Hodgkinson, A. (1961). Renal phosphate excretion indices in the diagnosis of hyperparathyroidism. Clinical Science, 21 , 125-132.

Noonan, J. A. (1968). Hypertelorism with Turner phenotype. American Journal of Diseases of Children, 116, 373-380.

Pergament, E., Pietra, G. C., Kadotani, T., Sato, H., and Berlow, S. (1970). A ring chromosome No. 16 in an infant with primary hypoparathyroidism. Journal of Pediatrics, 76, 745-751.

Robinson, P. K., Carmichael, E. A., and Cumings, J. N. (1954). Idiopathic hypoparathyroidism. Quarterly Journal of Medicine, 23, 383-402.

Smith, D. W. (1970). Recognizable Patterns of Human Malformation, pp. 60-61. Saunders: Philadelphia.

Sugar, O. (1953). Central neurological complications of hypoparathyroidism. Archives of Neurology and Psychiatry, 70, 86-107.

Tuvemo, T., and Gustavson, K.-H. (1972). Idiopathic hypoparathyroidism in a girl with Turner's syndrome. Acta Paediatrica Scandinavica, 61, 724-728.

van der Werff ten Bosch, J. J. (1959). The syndrome of brachmetacarpal dwarfism ('pseudo-pseudohypoparathyroidism') with and without gonadal dysgenesis. Lancet, 1, 69-71. 